\title{
Kajian Kapasitas Sungai Sengkarang Kabupaten Pekalongan Dengan Menggunakan HEC-RAS
}

\author{
JB Among Timur ${ }^{1}$, Abraham Daksa B D ${ }^{1}$, Budi Santosa ${ }^{2}$ \\ email: amongxii.ipa3@gmail.com \\ abrahamdaksabd@gmail.com \\ ${ }^{1}$ Program Studi Teknik Sipil, Fakultas Teknik, Universitas Katolik Soegijapranata, Jl. Pawiyatan \\ Luhur IV/1, Bendan Dhuwur, Semarang 50234 \\ ${ }^{2}$ Dosen Program Studi Teknik Sipil, Fakultas Teknik, Universitas Katolik Soegijapranata, Jl. \\ Pawiyatan Luhur IV/1, Bendan Dhuwur, Semarang 50234
}

\begin{abstract}
Flooding was natural disasters the minimize the impact or can be avoided when you know a source of the problem. The increase in discharge flood most affected by the existence of the to watershed ( $D A S$ ), and the form of profile river that could not be accommodate flooding luminance stretch out. The purpose of this research is to evaluate capacity river Sengkarang in order to accommodate flooding luminance stretch out, and give the alternative solution flood. The necessary data in the form of rainfall daily from year 2001 - 2016 in five station rain, namely station Karang Gondang, PS.Kletak station, Karangsari station, Pekalongan station, and Kutosari station. Daily rainfall data is then processed into hourly rain data using Mononobe method. Then from the parameters that have been specified in the insert into HEC-HMS software. The result of HEC-HMS this is discharge flood simulations with the period repeated 2 annual of $322.8 \mathrm{~m} 3 / \mathrm{s}$, the period repeated 5 annual of 582.6 $\mathrm{m} 3 / \mathrm{s}$, the period repeated of 10 years of $765.1 \mathrm{m3} / \mathrm{s}$, the period repeated 25 annual of $1034.3 \mathrm{~m} 3 /$ $s$, the period repeated 50 annual of $1148.9 \mathrm{~m} 3 / \mathrm{s}$. after obtained discharge simulations with the period repeated certain then afterward did the simulation profile river sengkarang by using HEC-RAS software. This permodelan it can be found in which a part is happened flood. Therefore done solution altermatif of normalization river.
\end{abstract}

Keywords : Watershed (DAS),HEC-HMS,HEC-RAS, flood discharge

\section{PENDAHULUAN}

\subsection{Latar Belakang}

Sungai merupakan salah satu
sumber daya air yang banyak dimanfaatkan untuk memenuhi kebutuhan air setiap makhluk hidup. Salah satu sumber air dari sungai adalah air hujan.

Indonesia tercatat memiliki lebih dari 500 sungai besar dan kecil, 30\% diantaranya melewati kawasan padat penduduk, yang berpotensi menimbulkan banjir pada wilayah tersebut. (Depkes RI, 2006). Apabila sudah memasuki musim penghujan, beberapa daerah di Indonesia mengalami musibah banjir. Salah satu faktor penyebab terjadinya musibah banjir adalah volume air yang sangat besar dan tidak dapat ditampung oleh penyimpan air yang ada di daerah tersebut. Salah satu daerah yang memiliki potensi bencana banjir adalah Kabupaten Pekalongan.

Pekalongan dibagi menjasi dua wilayah administrative yaitu wilayah Kabupaten Pekalongan, dan wilayah Kotamadya Pekalongan. Kabupaten Pekalongan mengalir salah satu sungai 
yaitu Sungai Sengkarang. Sungai Sengkarang memiliki panjang $51.5 \mathrm{~km}$ yang terbentang dari hulu di Gunung Rogojembangan dan memiliki hilir di laut Jawa.

Seringkali di daerah hilir sungai mengalami musibah banjir, untuk itu perlu dilakukan suatu evaluasi mengenai kapasitas penampang sungai sebagai upaya dalam mengatasi musibah banjir yang terjadi setiap tahun.

\subsection{Rumusan Masalah}

Meluapnya sungai Sengkarang menimbulkan kerugian baik materi maupun non materi terhadap warga sekitar. Untuk itu diperluan evaluasi kapasitas penampang sungai Sengkarang.

\subsection{Tujuan Penelitian}

Tujuan dari penulisan laporan tugas akhir ini adalah:

a. Mengetahui kapasitas eksisting Sungai Sengkarang.

b. Menghitung debit rencana Sungai Sengkarang dengan periode ulang 2 tahun, 5 tahun, 10 tahun, 25 tahun, dan 50 tahun.

c. Mengevaluasi kapasitas eksisting Sungai Sengkarang dalam menampung debit banjir rencana, serta memberikan solusi alternatif mengatasi banjir.

d. Mengidentifikasi penyebab utama terjadinya banjir.

\section{TINJAUAN PUSTAKA}

\subsection{Siklus Hidrologi}

Siklus Hidrologi adalah gerakan air laut ke udara, yang kemudian jatuh ke permukaan tanah lagi sebagai hujan atau bentuk presipitasi lain, dan akhirnya mengalir ke laut kembali.

\subsection{Hujan}

Menurut Triatmodjo (2010) hujan adalah bentuk presipitasi berbentuk air dari atmosfer yang jatuh sampai ke permukaan bumi; yang bisa berupa hujan, hujan salju, kabut, embun dan hujan es.

2.2.1 Pemilihan Jenis Sebaran

a. Distribusi Gumbel (Soemarto, 1999)

$$
X_{T}=\bar{X}+\frac{S}{S}\left(Y-Y_{n}\right)
$$

b. Distribusi Normal (Soemarto, 1999)

$$
X_{T}=\bar{X}+K_{T} \times S
$$

c. Distribusi Log Person III Soewarno (1995)

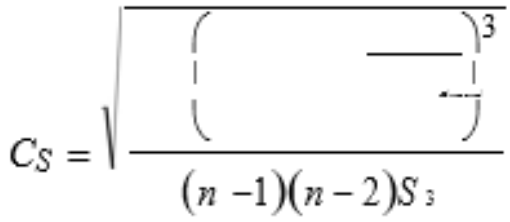

$$
\log X_{i}=\overline{\log X}+K_{T} \times S
$$

d. Distribusi Log Normal (Soemarto, 1999)

$$
X_{T}=\bar{X}+K_{T} \times S
$$

\subsection{Pengujian Kecocokan Sebaran}

Pengujian kecocokan sebaran digunakan untuk menguji apakah sebaran tersebut dapat memenuhi syarat untuk data perencanaan. Pengujian kecocokan dapat dilakukan 2 cara.

a. Perhitungan Chi Kuadrat

b. Perhitungan Smirnov Kolmogorov

\subsection{Banjir}

Satu definisi banjir menurut Suripin (2004) adalah suatu kondisi di mana tidak tertampungnya air dalam saluran pembuang (palung sungai) atau terhambatnya aliran air di dalam saluran pembuang, sehingga meluap menggenangi daerah (dataran banjir) sekitarnya. 


\subsection{Sungai}

Sungai atau saluran terbuka menurut Triatmodjo (2010) adalah saluran dimana terdapat air mengalir dengan muka air bebas. Pada saluran terbuka, misalnya sungai (saluran alam), variabel aliran sangat tidak teratur terhadap ruang dan waktu.

\subsection{Daerah Aliran Sungai}

Daerah aliran sungai (DAS) adalah daerah yang dibatasi oleh punggung-punggung / pegunungan dimana air hujan yang jatuh didaerah tersebut akan mengalir menuju sungai utama pada suatu titik/stasiun yang ditinjau (Triatmodjo, 2010).

\subsection{Metode Hidrologi}

Menurut Harto (1993), model hidrologi adalah sebuah sajian sederhana (simple representation) dari sebuah sistem hidrologi yang kompleks.

\subsection{HEC-HMS}

Hydrologic Engineering Centre (HEC) - Hydrologic Modeling System (HMS) merupakan salah satu model hidrologi yang masuk dalam kategori model matematik yang dikembangkan oleh Hydrologic Engineering Centre (HEC) dari US Army Corps Of Engineers (Arlen, 2000).

\subsection{HEC-RAS}

HEC-RAS adalah singkatan dari Hydraulic Engineering Centre-River Analysis System. HEC-RAS merupakan program aplikasi yang didesain untuk memodelkan aliran di sungai, Program River Analysis System (RAS), yang dibuat oleh Hydrologic Engineering Center (HEC) yang merupakan satu divisi di dalam Institute for Water Resources (IWR), di bawah US Army Corps of Engineers (USACE). HEC-RAS merupakan model satu dimensi aliran permanen maupun tak permanen (steady and unsteady one-dimensional flow model) (Istiarto, 2014).

\section{METODE PENELITIAN \\ 3.1 Tahapan Penelitian}

Dalam diagram alir berikut ditunjukan diagram alir secara umum dan menyeluruh mengenai Kajian Kapasitas Sungai Sengkarang dengan menggunakan HEC-RAS.

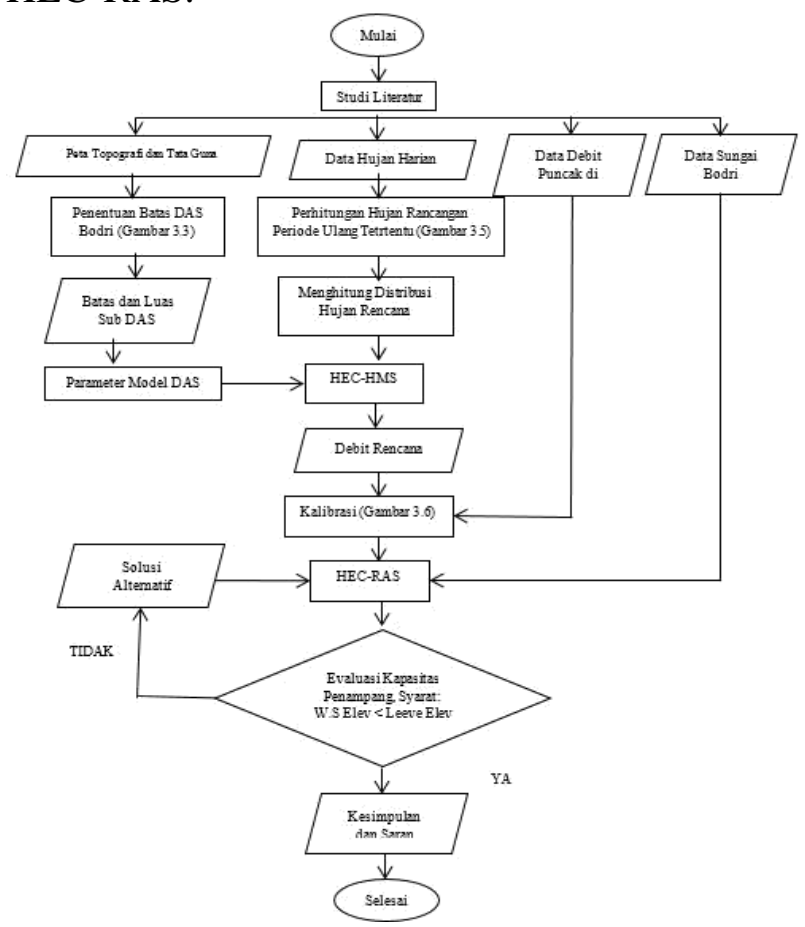

Gambar 3.1 Bagan Alir Penelitian

\subsection{Tahapan Analisis}

Analisis dilakukan dalam beberapa tahapan, yaitu:

1. Mempersiapkan data yang akan diolah

a. Curah hujan harian maksimum

b. Data geometri Sungai Sengkarang

2. Penentuan batas DAS dan membagi menjadi Sub DAS

3. Penentuan area Poligon Thiessen

4. Penentuan distribusi hujan rancangan 
5. Penentuan parameter awal yang digunakan

a. Curve number $(\mathrm{CN})$

b. Impervious (\%)

c. Lag time.

6. Menghitung besar debit puncak banjir lapangan

7. Input data parameter awal kedalam software HEC-HMS

8. Kalibrasi parameter awal dan didapatkan debit puncak banjir simulasi

9. Penentuan parameter awal yang digunakan pada HEC-RAS

a. Geometri saluran sungai

b. Nilai kekerasan manning

c. Data aliran untuk analisis hidrologi

10. Input data geometri dan debit rencana Kedalam software HEC-RAS

11. Analisa Sungai Sengkarang kondisi eksisting terhadap debit banjir

12. Memberikan solusi alternatif.

\subsection{Parameter Penelitian}

Pada penelitian ini pemodelan yang digunakan adalah software HECHMS dan HEC-RAS.

\section{PEMBAHASAN}

Setelah dilakukan pengolahan data distribusi hujan jam-jaman dan karakteristik DAS Sengkarang, selanjutnya dapat dilakukan simulasi debit puncak banjir menggunakan software HEC-HMS. Hasil dari simulasi menggunakan HEC-HMS berupa besar debit puncak banjir yang selanjutnya dapat di gunakan untuk input data software HEC-RAS. Setelah melakukan simulasi dengan debit banjir rencana maka diketahui bahwa kapasitas Sungai Sengkarang tidak dapat cukup menampung air, dimana air diharuskan tidak melebihi kapasitas penampang. Dalam kajian ini solusi alternatif yang dilakukan adalah berupa normalisasi sungai

\subsection{Analisa Debit Puncak Banjir Hasil Output Software HEC-HMS}

Setelah dilakukan seluruh tahapan dalam software HEC-HMS, maka dilakukan simulation run sehingga mendapatkan data output berupa peak discharge (debit puncak) dengan periode ulang tertentu yaitu 2 tahun, 5 tahun, 10 tahun, 25 tahun, dan 50 tahun.

Tabel 4.1 Debit Banjir Rencana Sungai Sengkarang

\begin{tabular}{|c|c|}
\hline Periode & Debit Banjir \\
\hline Periode 2 Tahunan & $322.8 \mathrm{~m}^{3} / \mathrm{s}$ \\
\hline Periode 5 Tahunan & $582.6 \mathrm{~m}^{3} / \mathrm{s}$ \\
\hline Periode 10 Tahunan & $765.1 \mathrm{~m}^{3} / \mathrm{s}$ \\
\hline Periode 25 Tahunan & $1034.3 \mathrm{~m}^{3} / \mathrm{s}$ \\
\hline Periode 50 Tahunan & $1148.9 \mathrm{~m}^{3} / \mathrm{s}$ \\
\hline
\end{tabular}

Berdasarkan tabel 4.1, dapat dilihat peningkatan debit puncak banjir dari periode 2 tahunan sampai periode 50 tahunan. Hal itu disebabkan pula dengan adanya pertambahan dalam penggunaan lahan pada DAS Sengkarang dan intesitas hujan yang tinggi .

\subsection{Analisa Hasil Output Simulasi HEC-RAS Eksisting}

Setelah dilakukan seluruh tahapan dalam software HEC-RAS, maka dilakukan simulation run sehingga dapat diketahui bentuk penampang sungai, tinggi muka air dan kapasitas Sungai Sengkarang mencukupi atau tidak, contoh hasil output dari simulasi HEC-RAS dengan periode ulang 50 tahunan dapat dilihat pada Gambar dibawah ini. 


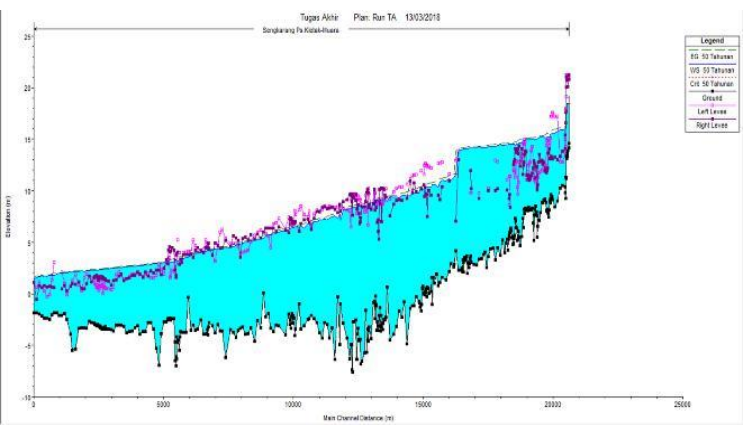

Gambar 4.1 Profil Muka Air Eksisting terhadap Debit Banjir Rencana 50 tahun

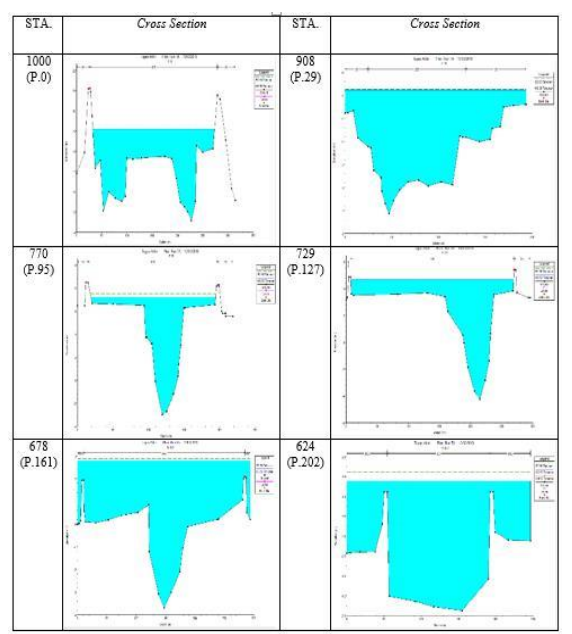

Gambar 4.2 Hasil Output HEC-RAS terhadap Debit Banjir Rencana 50 Tahun

Hasil Output HEC-RAS menunjukan profil muka air akibat debit rencana 50 tahunan dapat dilihat pada Gambar 4.1, sedangkan Gambar 4.2 menunjukan hasil simulasi HEC-RAS dibeberapa cross sectioon akibar debit banjir rencana 50 tahunan.

\subsection{Kapasitas Eksisting Sungai Sengkarang}

Setelah melakukan simulasi dengan debit banjir rencana maka diketahui bahwa kapasitas Sungai Sengkarang tidak dapat cukup menampung air, dimana air diharuskan tidak melebihi kapasitas penampang.

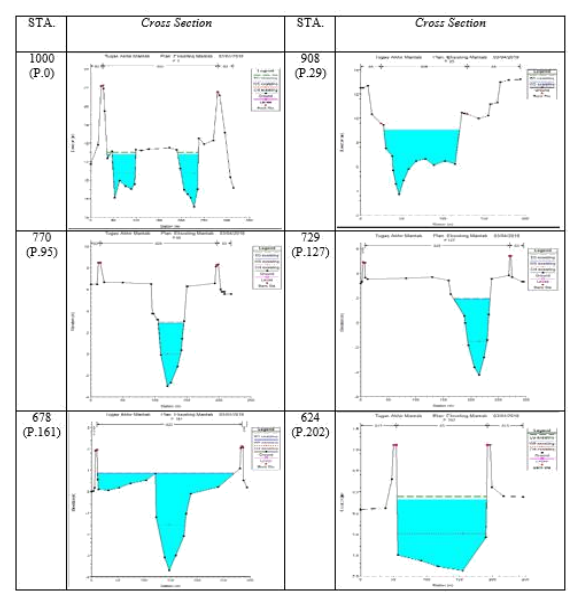

Gambar 4.3 Hasil Output HEC-RAS eksisting

Dalam kondisi eksisting Sungai Sengkarang hanya mampu menampung debit sebesar $221.907 \mathrm{~m}^{3} / \mathrm{dt}$. Dengan ketinggian air diatas mercu bendung Pesantren Kletak sebesar $90 \mathrm{~cm}$, apabila ketinggian air melebihi $100 \mathrm{~cm}$ dapat dikategorikan sebagai debit banjir. Gambar 4.12 menunjukan hasil output HEC-RAS terhadap kondisi eksisting Sungai Sengkarang di beberapa stasiun.

\subsection{Kondisi Sungai Sengkarang} Akibat Debit Banjir

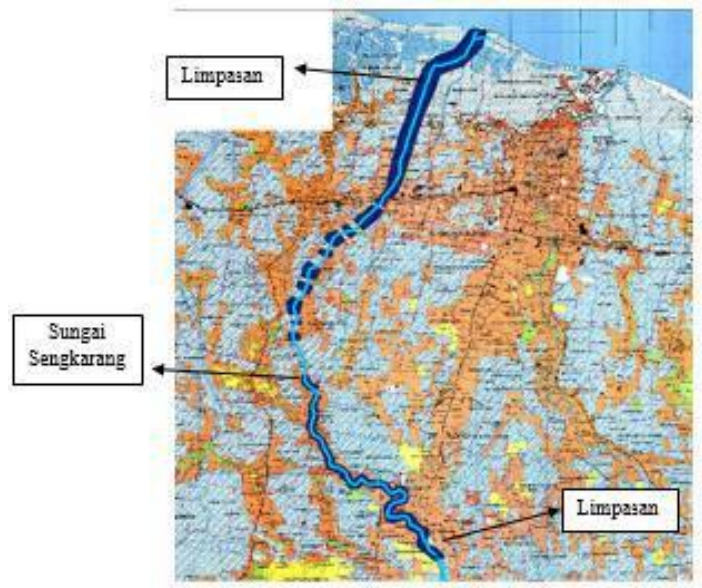

Gambar 4.4 Kondisis Sungai

Sengkarang yang terjadi Limpasan Akibat Debit Banjir Rencana 50 Tahunan 
Gambar 4.4 menunjukan lokasi dimana terjadi limpasan di Sungai Sengkarang akibat debit banjir rencana 50 tahunan Warna biru tua menunjukan daerah yang terjadi limpasan, sedangkan garis biru muda merupakan alur Sungai Sengkarang.

\subsection{Solusi Alternatif}

Dalam kajian ini solusi alternatif yang dilakukan adalah berupa normalisasi sungai.

Perbesaran penampang sungai yang baru akan mampu mengalirkan air sesuai dengan debit banjir rencana sebesar $1089.7 \mathrm{~m} 3 / \mathrm{dt}$, sehingga tidak terjadi luapan air dari penampang sungai. Perbesar dimensi penampang dilakukan mulai dari P 1+30 - P 202 yakni sepanjang $\pm 20.713 \mathrm{~km}$ dengan dimensi penampang dilakukan dengan bantuan HEC-RAS.

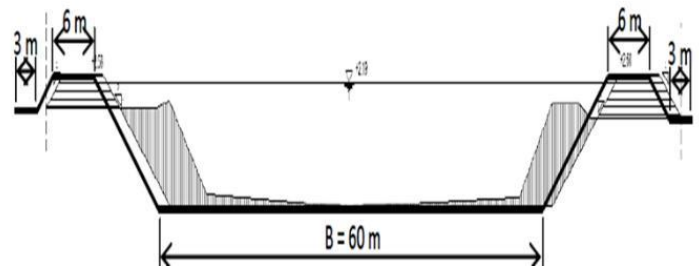

Gambar 4.18 Desain Potongan

Melintang Normalisasi Sungai

Sengkarang

\subsection{Hasil Output Simulasi HEC-RAS Normalisasi}

Setelah dilakukan perbaikan penampang, maka dilakukan simulation run sehingga dapat diketahui apakah bentuk penampang sungai, tinggi muka air dan kapasitas Sungai Sengkarang mencukupi atau tidak. Contoh hasil output dari simulasi HEC-RAS dapat dilihat pada Gambar 4.19.

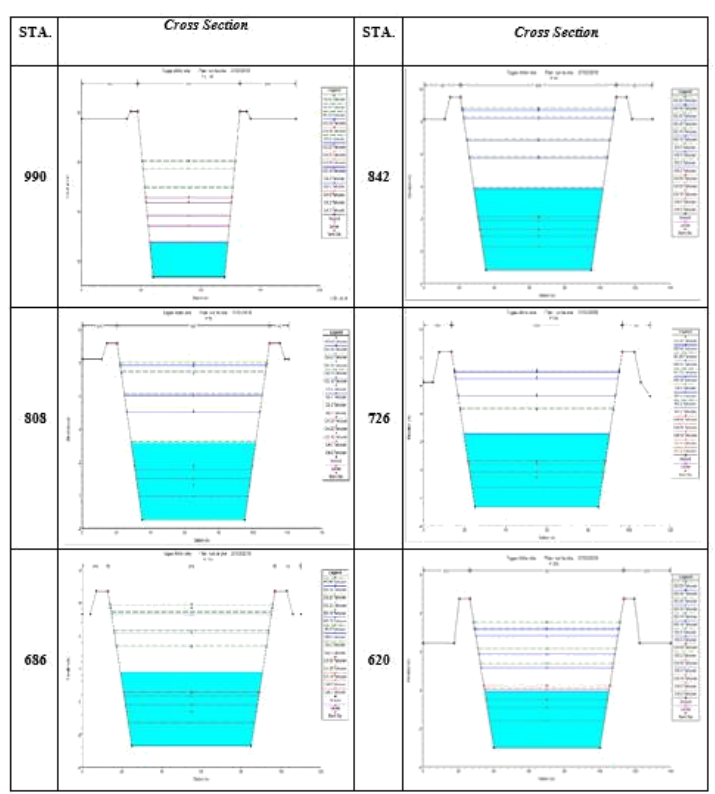

Gambar 4.19 Hasil Output HEC-RAS

Normalisasi

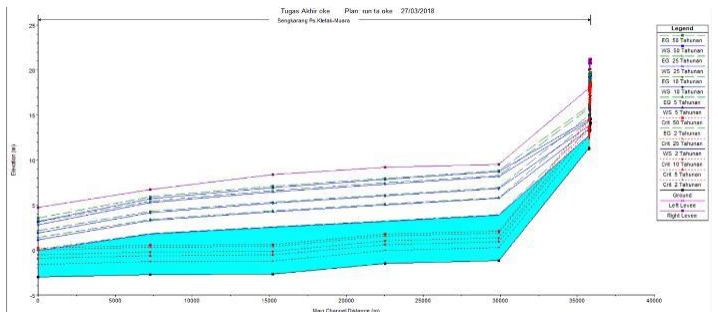

Gambar 4.20 Profil Muka Air Normalisasi

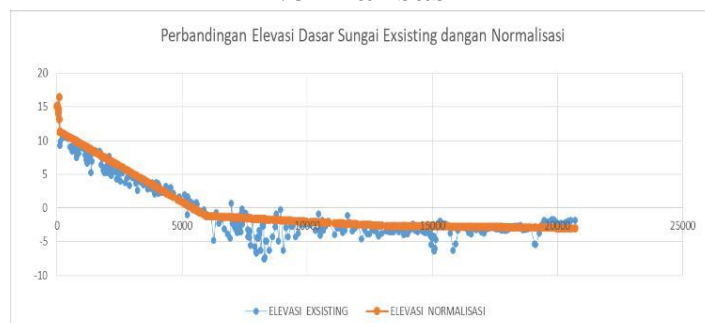

Gambar 4.20 Perbandingan Elevasi Dasar Sungai Exsisting dan Normalisasi

Gambar $\quad 4.19$ dan $\quad 4.20$ menunjukan profil muka air dan elevasi dasar sungai setelah dilakukan normalisasi. 


\section{KESIMPULAN DAN SARAN 5.1 Kesimpulan}

Kesimpulan yang dapat diambil dari hasil analisis yang sudah dilakukan adalah sebagai berikut:

1. Kapasitas Penampang Sungai Sengkarang pada kondisi eksisting dari hasil analisis menggunakan software HEC-RAS hanya mampu menampung debit sebesar 221.907 $\mathrm{m}^{3} / \mathrm{dt}$.

2. Debit banjir rencana Sungai Sengkarang untuk periode ulang 2 tahun sebesar

$322.8 \mathrm{~m}^{3} / \mathrm{dt}$, untuk periode ulang 5 tahun sebesar $582.6 \mathrm{~m}^{3} / \mathrm{dt}$, untuk periode ulang 10 tahun sebesar $765.1 \mathrm{~m}^{3} / \mathrm{dt}$, untuk periode ulang 25 tahun sebesar 1034.3

$\mathrm{m}^{3} / \mathrm{dt}$ dan untuk periode ulang 50 tahun sebesar $1148.9 \mathrm{~m}^{3} / \mathrm{dt}$,

3. Kondisi eksisting Sungai Sengkarang dengan debit kala ulang 2, 5, 10, 25 dan 50 tahun tidak dapat menampung debit yang direncanakan. Dalam kajian ini solusi alternatif yang dilakukan adalah berupa normalisasi sungai, dengan cara penyeragaman penampang sungai yang bermula pada STA 1000 (P.0) sampai dengan STA 620 (P.202) dengan jarak $\pm 20.713 \mathrm{~km}$.

\subsection{Saran}

Saran yang dapat diberikan dari hasil analisis yang sudah dilakukan adalah sebagai berikut:

1. Segera melakukan perbaikan penampang Sungai Sengkarang karena apabila tidak segera ditangani akan terus terjadi banjir hampir disetiap tahunya,
2. Meningkatkan upaya nonstruktural pengendalian banjir di Sungai Sengkarang yaitu dengan membuat regulasi dalam pengendalian banjir berupa Peraturan Pemerintah Daerah dengan sanksi hukum dan himbauan untuk jangan membuang sampah sembarangan dan mengadakan penghijauan di wilayah hulu Sungai Sengkarang sehingga dapat mengatasi permasalahan banjir dimasa mendatang.

3. Untuk mengatasi banjir di Sungai Sengkarang perlu perbaikan tata guna lahan di beberapa Sub DAS di bagian hulu agar air hujan tidak langsung mengalir ke hilir.

\section{DAFTAR PUSTAKA}

Bashay, Jordan Yusuf. 2017. Tugas Akhir Pengaruh Tata Guna Lahan Terhadap Hidrografi Sungai ( Studi Kasus Comal Hulu). Universitas Katolik Soegijapranata Semarang

Departemen Kesehatan Republik Indonesia. 2006. Banjir. Jakarta: http://www.depkes.go.id/developme nt/site/jkn/index.php?cid=13010400 004\&id=buku-banjir-2006 diakses tanggal tanggal 17 Oktober 2017

Istiarto. 2014. Modul Pelatihan Simulasi Aliran 1-Dimensi Dengan Bantuan Paket Program Hidrodinamika HECRAS. Universitas Gadjah Mada, http://istiarto.staff.ugm.ac.id/docs/hi dter/HECRAS\%20Dasar\%20Simple \%20Geometry\%20River\%20Okt12. pdf pada tanggal 8 Desember 2017 
Harjanto, Putra Abrar, Akhmad Imammudin. 2017. Tugas Akhir Evaluasi Kapasitas Penampang Sungai Bodri dengan Menggunakan HEC-RAS. Universitas Katolik Soegijapranata Semarang

Harto, Sri. 1991. Hidrologi Terapan. Yogyakarta: Biro Penerbit Keluarga Mahasiswa Teknik Universitas Gajah Mada.

KFM, Radio.2015. Banjir Sungai Sengkarang Membuat Jembatan Darurat Sasak Hancur ,http://www.kfmpekalongan.com/20 15/11/banjir-sungai-sengkarangmembuat.html?m=1 diakses pada tanggal 17 Oktober 2017.

Pemkab Pekalongan. 2011. Bupati Tinjau Banjir Pakisputih dan Galangpengampon, http://www.pekalongankab.go.id/fasi litas-web/interaktif/galeri-foto/195cegah-db-dengan-psn-lebihefektif/detail/852psn3.html?tmpl=component diakses pada tanggal 18 Oktober 2017.

Petunjuk Penggunaan Model HECHMS $\quad 3.5 \quad$ dari https://www.academia.edu/10950627 /PEDOMAN_HEC_HMS_3.5?auto= download diakses pada tanggal 8 Desember 2017

Rahmawati, Ima Puspita. Nunik Ardhiani. 2008. Laporan Tugas Akhir Sisitem Pengendalian Banjir Sungai Sengkarang (Normalisasi

Sungai). Universitas Diponegoro. Semarang
Soemarto, CD. 1986. Hidrologi Teknik. Surabaya: Usaha Nasional

Sosrodarsono, Suyono, dan Takeda, Kensaku. 2006. Hidrologi untuk Pengairan. Jakarta: Pradnya Paramita.

Unila.2013. Tinjauan Tentang Sungai.digilib.unila.ac.id/13013/8/II. pdf diakses pada tanggal 8 Desember 2017

USACE. 2000. HEC-HMS Technical Reference Manual. USACE-HEC., Davis, CA

USACE. 2001. Hydrology Modelling System HEC-HMS, User Manual, Version 2.1. USACE-HEC., Davis, CA

\section{USU .2010. Definisi Bencana} Banjir http://repository.usu.ac.id/bitstream/ handle/123456789/33906/Chapter\% 20II.pd?sequence $=4$ di akses pada tanggal 8 Desember 2017 